\title{
TRANSPARANSI INFORMASI PERUSAHAAN PADA BURSA EFEK INDONESIA, SINGAPURA, DAN THAILAND
}

\author{
AUREL SEPTIAN CHRISTPRATAMA \\ TARSISIUS RENALD SUGANDA \\ FITRI OKTARIANI \\ Universitas Ma Chung, Villa Puncak Tidak Blok N No. 1, Karangwidoro, Kec. Dau, Malang, Indonesia \\ asep06617@gmail.com
}

\begin{abstract}
The aim of this research is to prove the influence of legal system, economic development, inflation, culture, board size, proportion of independent directors, and ownership concentration to the level of disclosure in three countries namely Indonesia, Singapore and Thailand. The research sample consist of 84 listed manufacture companies in Indonesia, Singapore and Thailand Stock Exchange in 2017. Multiple linear regression and anova used in this research. The result showed legal system, economic development, board size and proportion of independent directors had positive effect on e-CTI. However, inflation, culture, ownership concentration did not affect e-CTI. Furthermore, the level of e-CTI in three different countries were identic.
\end{abstract}

Keywords: macroeconomic, microeconomic, e-CTI, Indonesia-Singapore-Thailand Stock Exchange

\begin{abstract}
Abstrak: Tujuan penelitian adalah untuk membuktikan pengaruh sistem hukum, perkembangan ekonomi, inflasi, faktor budaya, ukuran dewan direksi, proporsi direktur independen, dan konsentrasi kepemilikan terhadap tingkat pengungkapan pada tiga negara yaitu Indonesia, Singapura dan Thailand. Sampel penelitian terdiri atas 84 perusahaan manufaktur terdaftar di Bursa Efek Indonesia, Singapura, dan Thailand pada tahun 2017. Metode regresi linear berganda dan uji anova digunakan dalam penelitian ini. Hasil penelitian menunjukkan sistem hukum, perkembangan ekonomi, ukuran dewan direksi dan proporsi direktur independen berpengaruh positif terhadap tingkat pengungkapan e-CTI. Sedangkan, inflasi, faktor budaya, konsentrasi kepemilikan tidak berpengaruh terhadap tingkat pengungkapan e-CTI. Selain itu, tingkat pengungkapan e-CTI pada tiga negara adalah sama.
\end{abstract}

Kata kunci: makro ekonomi, mikro ekonomi, e-CTI, bursa efek Indonesia-Singapura-Thailand

\section{PENDAHULUAN}

\author{
Perkembangan teknologi menjadikan \\ internet sebagai instrumen dalam \\ menyebarkan informasi perusahaan yang \\ membentuk suatu komunikasi antara \\ perusahaan dengan para stakeholder (Giam \\ dan Breliastiti 2015). Penggunaan internet \\ menjadi salah satu media yang mendukung
}

keterbukaan dan transparansi pelaporan informasi karena dapat mengurangi tingkat asimetri informasi sehingga dapat mempercepat laju pertumbuhan perusahaan (Narsa dan Pratiwi 2017). Pelaporan informasi oleh suatu perusahaan disebut juga sebagai pengungkapan.

Wolk et al. (2013) mengatakan bahwa pengungkapan memiliki hubungan dengan 
informasi yaitu seperti laporan keuangan dan informasi lainnya termasuk peristiwa yang terjadi setelah tanggal laporan, catatan kaki, analisis dan diskusi manajemen, operasi dan ramalan keuangan, serta tambahan dalam laporan keuangan seperti pengungkapan segmental dan informasi pelengkap lebih dari biaya historis. Dengan adanya pengungkapan, investor dapat membuat keputusan yang tepat yang berdasarkan faktor-faktor yang berpengaruh pada risiko dan return investasi seperti faktor makro dan faktor mikro. Return dipengaruhi faktor makro seperti kebijakan fiskal dan moneter, industri yang sedang berkembang dan inflasi. Selain itu, faktor mikro seperti mutu dari manajemen, komposisi utang perusahaan dan komposisi modal (Ang 2012).

Dalam praktiknya, setiap negara memiliki tingkat pengungkapan informasi yang berbeda melalui internet. Hal ini disebabkan belum adanya regulasi untuk perusahaan dalam mengungkapkan pelaporan keuangannya melalui internet (Widari et al. 2018). Anna (2012) membuktikan bahwa negara yang berada di Asia Tenggara seperti Indonesia, Malaysia Singapura, dan Thailand mempunyai internet financial reporting yang berbeda-beda. Hal ini dikarenakan informasi yang disajikan di internet masih belum memiliki standar. Saat ini, pengungkapan informasi melalui internet termasuk dalam pengungkapan sukarela karena masih belum ada regulasi yang mengontrol mengenai informasi apa saja yang harus ditampilkan pada website perusahaan (Puspitaningrum dan Atmini 2012). Namun demikian, pengungkapan informasi perusahaan melalui internet sangat membantu investor dalam membuat keputusan yang tepat jika sudah ada keseragaman regulasi yang mengatur mengenai pengungkapan informasi perusahaan melalui internet.

Pengungkapan melalui internet dikenal dengan Corporate Information
Transparency on Internet (e-CTI) atau Internet Financial Reporting (IFR). Pengungkapan informasi melalui internet merupakan cara paling dasar bagi perusahaan untuk menunjukkan kinerja keuangan kepada stakeholders (Kamalluarifin dan Shafiy 2016). Hal tersebut mengharuskan perusahaan untuk mengungkapkan informasi sebanyak mungkin pada website perusahaannya. Tingkat transparansi informasi semakin tinggi maka semakin besar juga dampak yang diberikan investor terhadap pengambilan keputusan (Almilia dan Budisusetyo 2017).

Dalam studi ini, variabel yang akan dilakukan pengujian pengaruhnya terhadap tingkat pengungkapan e-CTI dibagi menjadi dua bidang yaitu makro dan mikro. Variabel makro terdiri atas sistem hukum, perkembangan ekonomi, inflasi, dan faktor budaya. Sedangkan, faktor mikro terdiri atas ukuran dewan direksi, proporsi direktur independen, dan konsentrasi kepemilikan. Studi ini merupakan perluasan dari penelitian yang dilakukan oleh Wiwin (2017). Perbedaan penelitian ini dengan penelitian yang dahulu terletak pada pemilihan sampel. Penelitian ini lebih mengfokuskan pada tiga negara yaitu Indonesia, Singapura dan Thailand karena data kapitalisasi pasar pada tahun 2017 yang dipublikasikan oleh World Bank menunjukkan nilai kapitalisasi terbesar terdapat pada Indonesia, Singapura dan Thailand.

Penelitian ini memiliki tujuan untuk membuktikan (1) pengaruh sistem hukum pada tingkat pengungkapan e-CTI. (2) Pengaruh perkembangan ekonomi pada tingkat pengungkapan e-CTI. (3) Pengaruh inflasi pada tingkat pengungkapan e-CTI. (4) Pengaruh budaya pada tingkat pengungkapan e-CTI. (5) Pengaruh ukuran dewan direksi pada tingkat pengungkapan eCTI. (6) Pengaruh proporsi direktur independen pada tingkat pengungkapan eCTI. (7) Pengaruh konsentrasi kepemilikan pada tingkat pengungkapan e-CTI. (8) Ketiga 
tingkat pengungkapan Indonesia, Singapura dan Thailand identik atau tidak identik.

\section{Stakeholder Theory}

Stakeholder

merupakan

perseorangan dan kelompok yang terpengaruh terlaksananya misi dari organisasi dan hingga waktunya tiba memberikan pengaruh terhadap terlaksananya tujuan-tujuan tersebut (Freeman 1984). Posisi para pemangku kepentingan yang dianggap memiliki kapabilitas yang kuat menjadi pertimbangan teori stakeholder. Kelompok stakeholder menjadi pertimbangan yang utama bagi perusahaan dalam menyajikan suatu informasi dalam laporan keuangan. Karyawan, pemegang saham, supplier, pelanggan, pemerintah, kreditor dan masyarakat merupakan stakeholder yang dimaksud (Lestari et al. 2016)

Teori stakeholder bertujuan bukan hanya laba yang menjadi tujuan utama perusahaan. Teori ini memiliki tujuan untuk melakukan pemberian manfaat bagi para stakeholdemya. Teori ini menjelaskan sebagai entitas, pihak yang memiliki kepentingan harus mendapatkan manfaat dari perusahaan. (Mandaika dan Salim 2017). Perusahaan dalam keberadaannya dipengaruhi oleh dorongan dimana diberikan oleh pemangku kepentingan terhadap perusahaan tersebut (Ghozali dan Chariri 2007). Gray et al. (1995) menjelaskan bahwa dukungan dari stakeholder terhadap jalannya perusahaan itu sangat penting dan dukungan tersebut didapatkan melalui kegiatan yang dilakukan perusahaan. Kekuatan dari stakholder semakin besar, maka usaha perusahaan dalam beradaptasi semakin besar juga.

Perusahaan dapat melakukan suatu cara dalam menjalin relasi dengan pemangku kepentingan adalah dengan pengungkapan sosial (Ghozali dan Chariri 2007). Pengungkapan sosial ditafsirkan sebagai cara komunikasi dari perusahaan terhadap semua stakeholder yang dimiliki perusahaan (Syafrullah dan Muharam 2017).

\section{Pengungkapan Informasi Perusahaan}

Pelaporan keuangan memiliki tujuan untuk memberikan informasi keuangan tentang entitas pelapor yang bermanfaat bagi investor masa kini dan investor yang memiliki potensi, dan kreditor lainnya dalam menerbitkan suatu keputusan mengenai sumber daya yang disediakan untuk entitas (IAI 2016). Hendriksen dan Van Breda (2010) mengatakan informasi yang diungkap tergantung pada kepandaian para pengguna informasinya. Keterangan yang tertera pada laporan keuangan harus mudah dipahami para pembaca yang memiliki pengertian yang memadai mengenai aktivitas ekonomi dan aktivitas bisnis serta dapat memahaminya dengan sungguh-sungguh. Pengungkapan yang terdapat dalam perusahaan diklasifikasikan menjadi dua jenis, yaitu pengungkapan sukarela (voluntary disclosure) dan pengungkapan wajib (mandatory disclosure) (Suwardjono 2016).

Pengungkapan wajib merupakan pengungkapan yang dilakukan industri tentang informasi-informasi krusial yang berhubungan dengan kegiatan dan situasi perusahaan secara nyata yang memiliki sifat wajib dan diatur oleh regulasi. Pengungkapan wajib pada tiap negara yang dijalankan perusahaan mungkin berbedabeda sesuai dengan hukum yang secara sah tertera di negara tersebut. Sedangkan, pengungkapan sukarela merupakan pengungkapan yang dilakukan industri selain yang telah ditetapkan oleh standar akuntansi atau regulasi institusi. Pengungkapan sukarela dilakukan perusahaan tanpa tekanan atau diwajibkan oleh peraturan yang resmi berlaku. Pengungkapan sukarela dapat membantu dalam meningkatkan kredibilitas perusahaan dan mengakomodasi investor dalam memahami strategi bisnis manajemen (Suwardjono 2016).

Corporate Information Transparency on the Internet (e-CTI) 
Corporate Information Transparency on the Internet (e-CTI) merupakan cara yang dilakukan institusi dalam memaksimalkan internet untuk memberikan informasi keuangan maupun non-keuangan. Selain itu, internet financial reporting diartikan sebagai penggunaan website perusahaan untuk menyebarkan informasi keuangan dan kinerja perusahaan (Parlakkaya et al. 2015).

Website memungkinkan manajemen untuk mengungkapkan informasi yang dikombinasikan dengan multimedia dan komunikasi interakfif sehingga memberikan fleksibilitas yang tidak tersedia dalam laporan keuangan dengan format kertas tradisional. Sehingga dari segi konten, pengungkapan berbasis websites menawarkan beberapa kelebihan dan peluang bagi perusahaan untuk membuat pengungkapan tentang berbagai aspek aktivitas mereka yang mencakup laporan tahunan, siaran pers, laporan triwulanan, materi tambahan seperti catatan Rapat Umum Pemegang Saham (RUPS) tahunan, pengungkapan mengenai kecukupan modal dan isu manajemen risiko (Cormier et al. 2009). Website perusahaan menjadi sumber informasi yang paling banyak dimanfaatkan dan sangat diperlukan bagi stakeholder karena websiter perusahaan menyediakan informasi keuangan dan non-keuangan dalam waktu nyata (Uyar 2012). Penggunaan website perusahaan dalam melakukan pengungkapan informasi secara sukarela sangat menarik bagi pasar dan telah menjadi praktik umum di antara perusahaanperusahaan yang terdaftar di seluruh dunia (Sanchez et al. 2011).

\section{Sistem Hukum}

Perusahaan akan lebih condong untuk berperilaku dengan responsibilitas dan akan mengungkapan kepada stakeholders mengenai perilakunya jika perusahaan tersebut menjalankan bisnisnya dalam area dengan tuntutan regulasi yang kuat dan sistem hukum yang mengarah pada penjagaan stakeholders (Campbell 2006). Kaymak dan Bektas (2017) dan Anggraita dan Syafiqurrahman (2013) membuktikan bahwa sistem hukum mempunyai pengaruh positif atas tingkat pengungkapan e-CTI. Sedangkan, Wiwin (2017) mengutarakan bahwa sistem hukum tidak memiliki pengaruh terhadap e-CTI. Oleh karena itu, hipotesis pertama dalam penelitian adalah sebagai berikut:

$\mathrm{H}_{1}$ : Sistem hukum berpengaruh positif terhadap tingkat pengungkapan e-CTI.

\section{Perkembangan Ekonomi}

Samaha dan Abdallah (2011) menyatakan bahwa pengungkapan informasi perusahaan di internet pada negara berkembang dengan pasar modal yang berkembang lebih rendah dibandingkan pada negara dengan pasar modal yang telah bertumbuh sempurna. Selain itu, Leung dan Verriest (2014) menyatakan bahwa perkembangan ekonomi semakin tinggi dalam suatu negara maka perusahaan semakin tinggi juga dalam mengungkapkan informasinya. Anggraita dan Syafiqurrahman (2013) dan Turrent dan Ariza (2012) mengutarakan bahwa perkembangan ekonomi berpengaruh positif atas tingkat pengungkapan e-CTI. Oleh karena itu, hipotesis kedua dalam penelitian adalah sebagai berikut:

$\mathrm{H}_{2}$ : Perkembangan ekonomi berpengaruh positif terhadap tingkat pengungkapan e-CTI.

\section{Inflasi}

Laba perusahaan yang dihasilkan oleh akuntansi dalam kondisi inflasi tidak menggambarkan status ekonomik perusahaan yang sesungguhnya karena didasarkan pada prinsip nilai historis sehingga muncul akuntansi inflasi yang menyatakan sepenuhnya laporan keuangan berdasar pada harga perolehan historis dengan penyesuaian terhadap perubahan daya beli mata uang dan menjadikan luas pengungkapan informasi oleh perusahaan menjadi meningkat (Suwardjono 2016). Anggraita dan Syafiqurrahman (2013) mengatakan inflasi berpengaruh positif atas 
tingkat pengungkapan e-CTI. Sedangkan Turrent dan Ariza (2012) menyatakan bahwa inflasi memiliki pengaruh negatif atas tingkat pengungkapan e-CTI. Oleh karena itu, hipotesis ketiga dalam penelitian adalah sebagai berikut: $\mathrm{H}_{3}$ : Inflasi berpengaruh positif terhadap tingkat pengungkapan e-CTI.

\section{Budaya}

Askary et al. (2008) mengatakan bahwa praktik akuntansi dipengaruhi oleh faktor budaya dalam suatu negara, seperti nilai-nilai, agama, dan politik. Oleh karena itu, akuntansi dan praktiknya akan berbeda pada tiap negara dengan budaya yang berbeda. oleh Anggraita dan Syafiqurrahman (2013) mengutarakan bahwa faktor budaya berdampak atas tingkat pengungkapan e-CTI. Oleh karena itu, hipotesis keempat dalam penelitian adalah sebagai berikut:

$\mathrm{H}_{4}$ : Budaya berpengaruh negatif terhadap tingkat pengungkapan e-CTI.

\section{Ukuran Dewan Direksi}

Ukuran dewan memainkan peran yang penting dalam mempengaruhi keputusan terutama untuk menentukan tingkat pengungkapan informasi perusahaan (Hashim et al. 2014). Ukuran dewan yang lebih besar dapat menumbuhkan volume pengungkapan informasi perusahaan. Kaymak dan Bektas (2017) dan Allegrini dan Greco (2013) mengatakan bahwa ukuran dewan berpengaruh positif atas pengungkapan Sedangkan, Elfeky (2017) mengatakan bahwa ukuran dewan tidak berpengaruh atas pengungkapan sukarela. Oleh karena itu, hipotesis kelima dalam penelitian adalah sebagai berikut:

$\mathrm{H}_{5}$ : Ukuran dewan direksi berpengaruh positif terhadap tingkat pengungkapan e-CTI.

\section{Proporsi Direktur Independen}

Elfeky (2017) menyatakan bahwa dengan banyaknya proporsi direktur independen dalam suatu perusahaan, direktur independen dapat mendorong manajemen dalam mengungkapkan informasi secara sukarela. Parlakkaya et al. (2015), Elfeky (2017), dan Kaymak dan Bektas (2017) mengatakan bahwa proporsi direktur independen memiliki pengaruh positif terhadap pengungkapan. Sedangkan, Puspitaningrum dan Atmini (2012) mengatakan bahwa direktur independen tidak mempunyai pengaruh terhadap pengungkapan. Oleh karena itu, hipotesis keenam dalam penelitian adalah sebagai berikut:

$\mathrm{H}_{6}$ : Proporsi direktur independen berpengaruh positif terhadap tingkat pengungkapan e-CTI.

\section{Konsentrasi Kepemilikan}

$\begin{array}{rrr}\text { Nugroho } & (2017) & \text { menyatakan } \\ \text { konsentrasi } & \text { kepemilikan } & \text { merupakan }\end{array}$ kepemilikan saham terbesar pada entitas ekonomi yang dapat dijadikan hak pengambilan suara dalam RUPS. Pemegang saham yang memiliki saham terbesar pada suatu perusahaan akan meminta manajemen untuk menunjukkan informasi penting lebih banyak dalam annual report. Ojah dan Mokoteli (2012), Turrent dan Ariza (2012), dan Elfeky (2017) mengatakan konsentrasi kepemilikan memiliki pengaruh negatif terhadap pengungkapan. Sedangkan, Whiting dan Woodcock (2011) mengatakan bahwa konsentrasi kepemilikan tidak mempunyai pengaruh terhadap pengungkapan. Oleh karena itu, hipotesis ketujuh dalam penelitian adalah sebagai berikut:

$\mathrm{H}_{7}$ : Konsentrasi kepemilikan berpengaruh negatif terhadap tingkat pengungkapan e-CTI.

\section{Perbedaan e-CTI antara Indonesia, Singapura, dan Thailand}

Tingkat pengungkapan e-CTI diukur dengan melakukan kompilasi terhadap beberapa data yang terbagi menjadi tiga sub indeks yaitu informasi tentang perusahaan, pelaporan keuangan, dan informasi tentang tata kelola perusahaan. Elemen-elemen dari masing-masing sub indeks dikumpulkan untuk mendapatkan indeks global sehingga tingkat pengungkapan e-CTI dari tiap negara tidak jauh 
berbeda (Turrent dan Ariza 2012). Penelitian yang dilakukan oleh Wiwin (2017) mengatakan bahwa e-CTI memiliki nilai yang tidak berbeda. Oleh karena itu, hipotesis kedelapan dalam penelitian adalah sebagai berikut:

$\mathrm{H}_{8}$ : Ketiga rata-rata tingkat pengungkapan e-CTI adalah identik atau sama.

\section{METODE PENELITIAN}

Penelitian ini menggunakan sampel perusahaan manufaktur yang terdaftar di Bursa Efek Indonesia (LQ45), Singapura (STI), dan Thailand (SET50). Kriteria pengambilan sampel yang digunakan dalam penelitian adalah sebagai berikut:

a. Perusahaan memiliki situs web pribadi yang dapat diakses.

b. Perusahaan mengungkapkan laporan keuangan dan laporan tahunan untuk tahun 2017.

c. Masa pelaporan perusahaan berakhir pada bulan Desember. Kriteria ini digunakan untuk meningkatkan komparabilitas nilai dari variabelvariabel yang dilakukan penelitian.

d. Mata uang pada laporan perusahaan adalah mata uang resmi negara. Kriteria ini digunakan untuk meningkatkan komparabilitas nilai variabel kontrol ukuran perusahaan.

Corporate Information Transparency on the Internet (e-CTI) atau Internet Corporate Reporting (ICR) atau Internet Financial Reporting (IFR) merupakan cara yang dilakukan perusahaan dalam memanfaatkan internet untuk menyerbarkan informasi finansial maupun non-finansial. Variabel e-CTI diukur berdasar pada indeks e-CTI yang mengacu pengukuran indikator yang terdapat pada studi yang dilakukan oleh Turrent dan Ariza (2012). Persentase dalam indeks menunjukkan bahwa setiap item yang terdapat pada indeks mempunyai nilai sama dalam pengukuran eCTI. Pengukuran angka e-CTI ini memakai variabel dummy yaitu setiap poin yang terdapat pada website perusahaan diberi angka 1 dan yang tidak terdapat pada website diberi angka 0 . Kemudian, jumlah angka yang didapatkan dibagi dengan jumlah item dalam indeks pengukuran e-CTI.

Sistem hukum diukur dengan menggunakan rata-rata nilai dari government effectiveness, control of corruption, political stability and the absence of violence, rule of law, regulatory quality, dan voice and accountability pada Worldwide Governance Indicator (WGI) yang didapatkan pada situr resmi Bank Dunia. Penggunaan proksi ini merujuk pada penelitian Turrent dan Ariza (2012).

Perkembangan ekonomi diukur dengan menggunakan proksi GDP (Gross Domestic Product) per kapita yang didapatkan melalui website Bank Dunia. Penggunaan proksi ini merujuk pada penelitian Turrent dan Ariza (2012).

Inflasi diukur dengan menggunakan proksi rata-rata inflasi tahunan yang didapatkan melalui website Bank Dunia. Penggunaan proksi ini merujuk pada penelitian Turrent dan Ariza (2012).

Budaya diukur dengan menggunakan proksi rata-rata nilai individualism, power distance, uncertainty avoidance, masculinity, indulgence dan long term orientation pada indeks budaya yang dikembangkan oleh 
Tabel 1 Kriteria Pengambilan Sampel

\begin{tabular}{|c|c|c|c|c|}
\hline No & Kriteria & Indonesia & Singapura & Thailand \\
\hline 1 & $\begin{array}{l}\text { Perusahaan yang tercantum dalam indeks saham } \\
\text { paling likuid }\end{array}$ & 45 & 30 & 50 \\
\hline 2 & $\begin{array}{l}\text { Perusahaan yang tercantum dalam indeks saham } \\
\text { paling likuid secara tidak langsung }\end{array}$ & (5) & (3) & (9) \\
\hline 3 & Perusahaan yang websitenya tidak dapat diakses & (0) & (1) & (0) \\
\hline 4 & $\begin{array}{l}\text { Perusahaan dengan data laporan tahunan dan } \\
\text { laporan keuangannya tidak lengkap }\end{array}$ & (1) & (0) & (0) \\
\hline 5 & $\begin{array}{l}\text { Perusahaan yang periode pelaporannya tidak } \\
\text { berakhir pada bulan Desember }\end{array}$ & (0) & (7) & (2) \\
\hline \multirow[t]{2}{*}{6} & $\begin{array}{l}\text { Perusahaan yang mata uang pelaporannya bukan } \\
\text { mata uang resmi negara }\end{array}$ & (4) & (7) & (2) \\
\hline & Total perusahaan yang digunakan sebagai sampel & 35 & 12 & 37 \\
\hline
\end{tabular}

Hofstede et al. (2010). Penggunaan proksi ini merujuk pada penelitian Askary et al. (2008).

Pengukuran ukuran dewan direksi memakai total dewan direksi yang dapat diperoleh melalui laporan tahunan perusahaan. Penggunaan proksi ini merujuk pada penelitian Turrent dan Ariza (2012)

Proporsi direktur independen diukur dengan menggunakan jumlah direktur independen terhadap jumlah total direksi yang dapat diperoleh melalui laporan tahunan perusahaan. Penggunaan proksi ini merujuk pada penelitian Turrent dan Ariza (2012).

Konsentrasi kepemilikan merupakan jumlah kepemilikan saham yang paling besar dalam perusahaan yang dapat dijadikan voting right dalam RUPS. Rata - rata dari persentase saham biasa digunakan untuk mengukur konsentrasi kepemilikan yaitu pemegang saham mayoritas dengan persentase saham melebihi $5 \%$. Data dapat diakses melalui laporan tahunan perusahaan.

Variabel kontrol dalam studi ini menggunakan ukuran perusahaan, jenis industri, profitabilitas dan leverage. Ukuran perusahaan ditentukan dengan menggunakan proksi log natural dari total aset. Jenis industri menggunakan pengukuran variabel dummy. Perusahaan yang merupakan sektor manufaktur diberi angka 1 , sedangkan perusahaan yang bukan merupakan sektor non-manufaktur diberi angka 0 . Kemudian, jumlah angka yang didapat dibagi dengan total perusahaan. Pengukuran pada profitabilitas menggunakan rumus dari Return on Assets (ROA). Leverage diproksikan dengan menggunakan rumus dari Debt to Equity Ratio (DER). Studi ini menggunakan persamaan regresi linear yang dijabarkan sebagai berikut: eCTI $=\alpha+\beta_{1} W G \mid+\beta_{2} G D P+\beta_{3} I N F+\beta_{4} F B+\beta_{5} T D+\beta_{6}$ $D I+\beta_{7} K K+\beta_{8} S Z+\beta_{9} J \mid+\beta_{10} R O A+\beta_{11} D E R+e$

Keterangan:

e-CTI : Corporate Information Transparency on the Internet

a : konstanta

WGI : sistem hukum

GDP : perkembangan ekonomi

INF : inflasi

FB : faktor budaya

TD : ukuran dewan direksi

DI : proporsi direktur independen

KK :konsentrasi kepemilikan

SZ : ukuran perusahaan

$\mathrm{JI} \quad$ : jenis industri

ROA : profitabilitas

ROE : leverage

e : error 


\section{HASIL DAN PEMBAHASAN}

Statistik deskriptif yang terdapat dalam penelitian dapat dilihat dalam tabel 2. Dalam penelitian ini, variabel sistem hukum, perkembangan ekonomi, inflasi dan budaya dipisah dalam model penelitian agar tidak terjadi masalah dalam multikolinearitas. Hal ini dikarenakan keempat variabel tersebut memiliki korelasi yang kuat dalam penelitian.

Sistem hukum mempunyai nilai sig sebesar 0,040 sehingga nilai sig lebih kecil dari 0,05 . Hal ini memiliki arti bahwa sistem hukum berpengaruh positif atas tingkat pengungkapan e-CTI sehingga $\mathrm{H}_{1}$ yang terdapat dalam studi ini diterima. Hasil studi ini sama dengan hasil studi dari Anggraita dan Syafiqurrahman (2013) dan Turrent dan Ariza (2012). Sistem hukum memainkan peran yang penting dalam mempengaruhi tingkat transparansi perusahaan atau tingkat pengungkapan e-CTI dalam masing-masing negara (Turrent dan Ariza 2012).

Perusahaan yang terdapat dalam suatu negara dengan sistem hukum yang berorientasi pada stakeholder dan dengan mekanisme penegakan hukum yang kuat lebih memungkinkan untuk membuat laporan yang terintegrasi. Adanya undang-undang dan peraturan yang lebih ketat dapat sangat membatasi aktivitas perusahaan tertentu yang saat ini dilakukan secara sukarela sehingga mengurangi manfaat yang diperoleh masyarakat dari mereka. Selain itu, norma-norma umum dan mekanisme penegakan yang mengatur mengenai hak-hak pemangku kepentingan dapat memiliki dampak signifikan pada praktik pengungkapan (Frias-Aceituno et al. 2013).

Perkembangan ekonomi mempunyai nilai sig sebesar 0,040 sehingga nilai sig tidak melebihi 0,05. Hal ini memiliki arti bahwa perkembangan ekonomi berpengaruh positif terhadap tingkat pengungkapan e-CTI sehingga $\mathrm{H}_{2}$ yang terdapat dalam studi ini diterima. Hasil studi ini sama dengan hasil studi dari Anggraita dan Syafiqurrahman (2013) dan Turrent dan
Ariza (2012). Semakin tinggi perkembangan ekonomi dalam suatu negara maka perusahaan semakin tinggi juga dalam mengungkapkan informasinya (Leung dan Verriest 2014).

Inflasi mempunyai nilai sig sebesar 0,887 sehingga nilai sig lebih besar dari 0,05 . Hal ini memiliki arti bahwa inflasi tidak mempunyai pengaruh terhadap tingkat pengungkapan e-CTI sehingga $\mathrm{H}_{3}$ dalam penelitian ini tidak diterima. Hasil studi ini berbeda dengan studi dari Turrent dan Ariza (2012) dan Anggraita dan Syafiqurrahman (2013) yang menyatakan bahwa inflasi mempunyai pengaruh positif terhadap tingkat pengungkapan e-CTI. Kewal (2012) mengutarakan Bank Indonesia mengatur tinggak inflasi di Indonesia sehingga jika tingkat inflasi mencapai $10 \%$, maka suku bunga Bank Indonesia akan dinaikan untuk mendorong investor memindahkan modalnya ke sektor perbankan. Kemudian, jika tingkat inflasi kurang dari $10 \%$ maka inflasi tidak berpengaruh terhadap keputusan investor sehingga informasi dalam pengungkapan tidak diperbanyak oleh perusahaan untuk memikat perhatian investor.

Faktor budaya memiliki nilai sig sebesar 0,474 sehingga nilai sig lebih besar dari 0,05. Hal ini memiliki arti bahwa faktor budaya tidak mempunyai pengaruh terhadap tingkat pengungkapan e-CTI sehingga $\mathrm{H}_{4}$ dalam penelitian ini tidak diterima. Hasil studi ini bertentangan dengan studi yang dilakukan Anggraita dan Syafiqurrahman (2013) yang menyatakan faktor budaya mempunyai pengaruh negatif atas tingkat pengungkapan eCTI. Mir et al. (2016) mengutarakan perusahaan dalam melakukan pengungkapan sukarela merupakan peristiwa yang rumit dan faktor budaya masih belum memadai untuk memperkirakan pengungkapan yang dilakukan. Kegiatan pengungkapan didasari oleh elemen organisasi yang lain seperti ketentuan dalam industri, kompetisi pasar, dan kondisi lingkungan.

Ukuran dewan direksi mempunyai nilai sig yang berbeda-beda antara model 1 , 
model 2, model 3, dan model 4. Namun, semua nilai sig tersebut mempunyau nilai yang tidak melebihi 0,05. Hal ini menunjukkan arti bahwa ukuran dewan direksi berpengaruh sehingga $\mathrm{H}_{5}$ yang dalam studi ini diterima. Hasil studi ini sejalan dengan hasil studi dari Wiwin (2017), Kaymak dan Bektas (2017), dan Allegrini dan Greco (2013). Ukuran dewan direksi memainkan peran yang penting dalam mempengaruhi keputusan terutama untuk menentukan tingkat pengungkapan informasi perusahaan (Hashim et al. 2014). Proporsi direktur independen memiliki nilai sig yang berbeda antara model 1, model 2, model 3, dan model 4. Namun, semua nilai sig dari model tersebut mempunyai nilai yang lebih kecil dari 0,05.

Tabel 2 Statistik Deskriptif

\begin{tabular}{|c|c|c|c|c|c|c|}
\hline & \multicolumn{2}{|c|}{ Indonesia } & \multicolumn{2}{|c|}{ Singapura } & \multicolumn{2}{|c|}{ Thailand } \\
\hline Variabel & Mean & $\begin{array}{l}\text { Standar } \\
\text { Deviasi }\end{array}$ & Mean & $\begin{array}{l}\text { Standar } \\
\text { Deviasi }\end{array}$ & Mean & $\begin{array}{l}\text { Standar } \\
\text { Deviasi }\end{array}$ \\
\hline e-CTI & 0,78577 & 0,40754 & 0,78483 & 0,50355 & 0,81530 & 0,026960 \\
\hline WGI & $-0,17500$ & 0,000000 & 1,61700 & 0,000000 & $-0,27300$ & 0,000000 \\
\hline GDP & 3846,86000 & 0,000000 & 57714,30000 & 0,000000 & 6595,00000 & 0,000000 \\
\hline INF & 3,80900 & 0,000000 & 0,59200 & 0,000000 & 0,66800 & 0,000000 \\
\hline FB & 47,66700 & 0,000000 & 44,66700 & 0,000000 & 43,16700 & 0,000000 \\
\hline TD & 7,49 & 1,976 & 9,92 & 2,151 & 13,11 & 2,536 \\
\hline DI & 0,07920 & 0,077276 & 0,69158 & 0,150045 & 0,41392 & 0,118109 \\
\hline KK & 0,49477 & 0,209585 & 0,15225 & 0,048535 & 0,26741 & 0,180812 \\
\hline$S Z$ & 31,55157 & 1,379159 & 21,74200 & 2,203769 & 25,78589 & 1,687186 \\
\hline J & 0,22857 & 0,978930 & 0,00000 & 0,000000 & 0,08108 & 0,276725 \\
\hline ROA & 0,08414 & 0,087348 & 0,03775 & 0,32817 & 4,3578 & 1,949797 \\
\hline DER & 1,98603 & 2,100733 & 3,07492 & 3,431063 & 2,22762 & 2,451722 \\
\hline
\end{tabular}

Tabel 3 Uji T

\begin{tabular}{ccccc}
\hline Variabel & $\begin{array}{c}\text { Model 1 } \\
\text { Sig }\end{array}$ & $\begin{array}{c}\text { Model 2 } \\
\text { Sig }\end{array}$ & $\begin{array}{c}\text { Model 3 } \\
\text { Sig }\end{array}$ & $\begin{array}{c}\text { Model 4 } \\
\text { Sig }\end{array}$ \\
\hline WGI & 0,040 & & & \\
GDP & & 0,040 & 0,887 & \\
INF & & & & 0,474 \\
FB & 0,000 & 0,000 & 0,003 & 0,014 \\
TD & 0,012 & 0,012 & 0,042 & 0,042 \\
DI & 0,581 & 0,581 & 0,576 & 0,634 \\
KK & 0,450 & 0,452 & 0,535 & 0,149 \\
SZ & 0,618 & 0,618 & 0,826 & 0,751 \\
JI & 0,460 & 0,461 & 0,870 & 0,779 \\
ROA & 0,590 & 0,590 & 0,719 & 0,650 \\
DER & & & & \\
\hline
\end{tabular}

Hal ini memiliki arti proporsi direktur independen memiliki pengaruh positif atas tingkat pengungkapan e-CTI sehingga $\mathrm{H}_{6}$ dalam studi ini diterima. Hasil studi ini sama dengan hasil studi dari Elfeky (2017), Kaymak dan Bektas (2017) dan Parlakkaya et al. (2015). 
Banyaknya proporsi direktur independen dalam sebuah korporasi, direktur independen dapat mendorong manajamen untuk mengungkapkan informasi secara sukarela (Elfeky 2017).

Konsentrasi kepemilikan memiliki nilai sig yang berbeda antara model 1 , model 2, model 3, dan model 4. Namun, semua nilai sig mempunyai nilai yang melebihi 0,05 . Hal ini memiliki arti bahwa konsentrasi kepemilikan tidak memiliki pengaruh atas tingkat pengungkapan e-CTI sehingga $\mathrm{H}_{7}$ dalam penelitian ini tidak diterima Hasil ini sama dengan hasil penelitian dari Anggratita \& Syafiqurrahman (2013) dan Puspitaningrum \& Atmini (2012). Kepemilikan perusahaan yang tersebar belum dapat memaksimalkan fungsinya dalam mengawasi kapasitas dari manajemen (Puspitaningrum dan Atmini 2012).

Variabel kontrol dalam penelitian seperti ukuran perusahaan, jenis industri, profitabilitas, dan leverage dalam studi ini berpengaruh atas tingkat pengungkapan e-CTI. Nilai sig dari e-CTI memperlihatkan angka sebesar 0,032. Nilai sig tersebut tidak melebihi 0,05 sehingga $\mathrm{H}_{8}$ diterima. Hal ini menjelaskan bahwa ketiga ratarata tingkat pengungkapan e-CTI di Indonesia, Singapura dan Thailand identik atau sama.

\section{PENUTUP}

Tujuan dalam penelitian adalah untuk melakukan analisis terhadap berbagai faktor dalam memberikan pengaruh terhadap Corporate Transparency on the Internet (e-CTI). Penelitian ini membuktikan sistem hukum, perkembangan ekonomi, ukuran dewan direksi dan proporsi direktur independen mempunyai pengaruh positif terhadap tingkat pengungkapan e-CTI. Inflasi, faktor budaya dan konsentrasi kepemilikan tidak memiliki pengaruh atas tingkat pengungkapan e-CTI. Sistem hukum memainkan peran yang penting dalam mempengaruhi tingkat transparansi perusahaan atau tingkat pengungkapan e-CTI dalam masing-masing negara. Industri dalam suatu negara dengan sistem hukum yang berorientasi kepada stakeholder dan dengan mekanisme penegakan hukum yang kuat lebih memungkinkan untuk membuat laporan yang terintegrasi. Kemudian, perkembangan ekonomi yang tinggi dalam suatu negara juga akan berpengaruh terhadap perusahaan yaitu perusahaan semakin tinggi juga dalam mengungkapkan informasinya. Industri yang terdapat dalam negara-negara dengan tingkat ekonomi yang tinggi biasanya cenderung untuk melakukan pengungkapan informasi perusahaan jika dibandingkan dengan negaranegara dengan tingkat ekonomi yang rendah.

Ukuran dewan direksi yang besar memainkan peran yang penting dalam mempengaruhi keputusan terutama untuk menentukan tingkat pengungkapan informasi perusahaan. Kemudian, proporsi direktur independen juga dapat mempengaruhi tingkat pengungkapan informasi perusahaan. Banyaknya proporsi direktur independen dalam suatu perusahaan juga dapat mendorong manajemen dalam mengungkapkan informasi secara sukarela.

Tingkat pengungkapan e-CTI negara Indonesia, Singapura dan Thailand memiliki rata-rata tingkat pengungkapan e-CTI yang hampir sama. Hal ini disebabkan oleh banyaknya fasilitas yang disediakan oleh internet dan akses informasi menjadi semakin mudah. Selain itu, beberapa faktor makro dan faktor mikro perusahaan tidak berdampak atas tingkat pengungkapan e-CTI. Pengungkapan informasi perusahaan melalui internet merupakan pengungkapan sukarela sehingga banyak perusahaan yang dalam mengungkapkan informasi perusahaannya cenderung tidak jauh berbeda. Hal ini dikarenakan belum adanya standar dalam membuat websiter perusahaan. Namun, manajemen juga berusaha untuk melakukan pengungkapan informasi sebanyak mungkin sehingga mampu memikat investor dalam melakukan investasi.

Keterbatasan yang terdapat dalam penelitian adalah adanya perbedaan format 
dalam laporan tahunan perusahaan dari negara Indonesia, Singapura dan Thailand. Kemudian, pada beberapa website terdapat sebagian informasinya yang masih menggunakan bahasa dari negara masing-masing meskipun peneliti sudah menggunakan pilihan bahasa Inggris dalam pilihan bahasa di website masing-masing negara.

Faktor makro seperti inflasi dan faktor budaya serta faktor mikro seperti konsentrasi kepemilikan tidak berdampak atas tingkat pengungkapan e-CTI. Penelitian selanjutnya diharapkan dapat menggunakan faktor makro yang lain seperti lingkungan sosial politik. Selain itu, penelitian selanjutnya juga dianjurkan untuk membagi konsentrasi kepemilikan menjadi dua yaitu kepemilikan institusional dan kepemilikan individual. Hal ini dilakukan karena dapat memiliki perbedaan pengaruh terhadap pengungkapan informasi yang dilakukan oleh perusahaan.

\section{REFERENCES:}

Allegrini, M., and G. Greco. 2013. "Corporate boards, audit committees and voluntary disclosure: evidence from Italian Listed Companies." Journal of Management \& Governance 17 (1): 187-216.

Almilia, L. S., and S. Budisusetyo. 2017. "Internet Financial Reporting: User perception in Indonesia." International Journal if Business Information Systems 25 (2): 241-255.

Ang, R. 2012. Buku Pintar Pasar Modal Indonesia. Jakarta: Media Soft Indonesia.

Anggraita , V. F., and Syafiqurrahman. 2013. "Transparansi Informasi Perusahaan Berbasis Internet (e-CTI) pada Perusahaan Yang Terdaftar di China (SSE50), India (NIFTY), dan Indonesia (LQ45)." Simposium Nasional Akuntansi XVI. Manado. 514-538.

Anna, Y. D. 2012. "Perkembangan Penggunaan Internet Financial Reporting di Negara-Negara Asia." Konferensi Nasional Sistem Informasi. Bali. 1383-1387.

Askary, S., H. Yadzifar, and D. Askarany. 2008. "Culture and accounting practices in Turkey." International Journal Accounting, Auditing, and Performance Evaluation 5 (1): 66-88.

Campbell, J. L. 2006. "Instituional Analysis and Paradox of Corporate Social Responsibility." American Behavioral Scientist 49 (7): 925-938.

Cormier, D., M. Leduox, and M. Magnan. 2009. "The Use of Web Sites as a Disclosure Platform for Corporate Performance." Internationa Journal of Accounting Information Systems 10 (1): 1-24.

Elfeky, M. I. 2017. "The extent of voluntary disclosure and its determinants in emerging markets: Evidence from Egpyt." The Journal of Finance and Data Science 3 (1): 45-59.

Freeman, R. E. 1984. Strategic Management: A Stakeholder Approach. New York: Cambridge University Press.

Frias-Aceituno, J. V., L. Rodriguez-Ariza, and I. M. Garcia-Sanchez. 2013. "Is integrated reporting determined by a country's legal system? An exploratory study." Journal of Cleaner Production 44: 45-55.

Ghozali, I., and A. Chariri. 2007. Teori Akuntansi. Semarang: Badan Penerbit Universitas Dipenogoro.

Giam, H. S., and R. Breliastiti. 2015. "Pengaruh Ukuran Perusahaan, Leverage dan Tipe Industri Terhadap Corporate Information Transparency On The Internet (e-CTI) Perusahaan LQ45." Jurnal Akuntansi Bisnis 8 (2): $1-31$.

Gray, R., R. Kouhy, and S. Lavers. 1995. "Corporate Social and Environmental Reporting: A Review Literature and a Longitudinal Study of UK Disclosure." Accounting, Auditing \& Accountability Journal 8: 47-77.

Hashim, M. H., A. Nawawi, and A. A. Salin. 2014. "Determinants of Strategic Information Disclosure-Malaysian Evidence." International Jpurnal of Business and Society 15 (3): 547-572.

Hendriksen, E. S., and M. F. Van Breda. 2010. Teori Akuntansi. Jakarta: Interaksa.

Hofstede, G., G. J. Hofstede, and M. Minkov. 2010. Cultures and Organizations: Software of the Mind. New York: McGraw Hill.

Ikatan Akuntan Indonesia. 2016. Exposure Draft Kerangka Konseptual Pelaporan Keuangan. Jakarta: Dewan Standar Akuntansi Keuangan Ikatan Akuntan Indonesia. 
Kamalluarifin, W., and W. F. Shafiy. 2016. "The Influence of Corporate Governance and Firm Characteristics on the Timeliness of Corporate Internet Reporting By Top 95 Companies in Malaysia." Procedia Economics and Finance 35: 156-165.

Kaymak, T., and E. Bektas. 2017. "Corporate Social Responsibility and Governance Information Disclosure in Multinational Corporations: CSR, governance, and disclosure in MNCs." Corporate Social Responsibility and Envrionmental Management 24: 555-569.

Kewal, S. S. 2012. "Pengaruh Inflasi, Suku Bunga, Kurs dan Pertumbuhan PDB Terhadap Indeks Harga Saham Gabungan." Jurnal Economia 8 (1): 53-64.

Lestari, S. D., H. Paramu, and H. Sukarno. 2016. "Pengaruh Intellectual Capital Terhadap Kinerja Keuangan Perbankan Syari'ah di Indonesia." Ekuitas: Jurnal Ekonomi dan Keuangan 20 (3): 346-366.

Leung, E., and A. Verriest . 2014. The Geography of Disclosure: Evidence form Segment Reporting. Hong Kong: The Chinese University of Hong Kong.

Mandaika, Y., and H. Salim. 2017. "Pengaruh Ukuran Perusahaan, Kinerja Keuangan, Tipe Industri Dan Financial Leverage Terhadap Pengungkapan Corporate Social Responsibility: Studi Empiris Pada Perusahaan Manufaktur Yang Terdaftar Di Bursa Efek Indonesia Tahun 2011-2013." Jurnal Akuntansi 2: 181-201.

Mir, M. Z., B. Chatterjee, and A. S. Rahman. 2016. "Culture and Corporate Voluntary Reporting." Managerial Auditing Journal 24 (7): 639-667.

Narsa, I. M., and F. F. Pratiwi. 2017. "Internet Financial Reporting, Pengungkapan Informasi Website, Luas Lingkup Pelaporan Internet, Dan Nilai Perusahaan." Ekuitas: Jurnal Ekonomi dan Kuenagan 18 (2): 259-273.

Nugroho, A. 2017. Pengaruh Leverage, Profitabilitas, Komisaris Independen, dan Konsentrasi Kepemilikan Terhadap Pengungkapan Intellectual Capital. Skripsi, Surakarta: Universitas Muhammadiyah Surakarta.

Ojah, K., and T. M. Mokoteli. 2012. "Internet financial reporting, infrastructures and corporate governance: An international analysis." Review of Development Finance 2 (2): 69-83.

Parlakkaya, R., U. Kahraman, and H. Cetin. 2015. "The Effects of the Corporate Governance on the Level of Internet Financial Reporting: Evidence from Turkish Companies." International Journal of Social, Behavioral, Educational, Economic, Business and Industrial Engineering 9 (3): 920-924.

Puspitaningrum, D., and S. Atmini. 2012. "Corporate Governance Mechanism and The Level of Internet Financial Reporting: Evidence from Indonesia Companies." Procedia Economis and Finance 9 (2): 157-166.

Samaha, K., and S. Abdallah. 2011. "Further Evidence on Web-Based Corporate Disclosure in Developed Versus Developing Countries: A Comparative Analysis of Nature and Determinants in Egpyt and the United Kingdom." International Journal of Disclosure and Governance 9 (2): 148-180.

Sanchez, I. G., L. R. Dominguez, and I. G. Alvarez. 2011. "Corporate Governance and Strategic Information on the Internet." Accounting, Auditing, \& Accountability Journal 24 (4): 471-501.

Suwardjono. 2016. Teori Akuntansi: Perekayasaan Pelaporan Keuangan. Yogyakarta: BPFE.

Syafrullah, S., and H. Muharam. 2017. "Analisis Pengaruh Kinerja Environmental, Social, Dan Governance (ESG) Terhadap Abnormal Return." Dipenogoro of Journal Management 2: 1-14.

Turrent, G. D., and L. R. Ariza. 2012. "Corporate Information Transparency on the Internet by Listed Companies in Spain (IBEX35) and Mexico (IPYC)." The International Journal of Digital Accounting Research 12 (18): 137.

Uyar, A. 2012. "Determinants of corporate reporting on the internet: An analysis of companies listed on the Istanbul Stock Exchange (ISE)." Managerial Auditing Journal 27 (1): 87-104.

Whiting, R., and J. Woodcock. 2011. "Firm Characteristics and intellectual capital disclosure by Australian companies." Journal of Human Resource Costing \& Accounting 15 (2): 102-126.

Widari, P. P., M. Saifi, and F. Nurlaily. 2018. "Analisis Internet Financial Reporting (IFR) (Pada Perusahaan Manufaktur Yang Go Public di Indonesia, Singapura dan Malaysia)." Jurnal Administrasi Bisnis (JAB) 56 (1): 100-109.

Wiwin. 2017. "Studi Corporate Information Transparency On The Internet (e-CTI) Pada Bursa Efek Thailand, Singapura, Malaysia dan Indonesia." Parsimonia 3 (3): 69-87.

Wolk, H. I., M. G. Tearney, and J. L. Didd. 2013. Accounting Theory: A Conceptual and Instituional Approach. Ohio: South-Western College Publishing. 